\title{
Research on Risk Management and Optimization of Government Industry Guidance Fund
}

\author{
Yifei Gong, Feifei Shi, Jialing Li \\ College of Economic and Management, Southwest University, Chongqing, China \\ Email:penghuan1234@126.com
}

How to cite this paper: Gong, Y.F., Shi, F.F. and Li, J.L. (2019) Research on Risk Management and Optimization of Government Industry Guidance Fund. iBusiness, 11, 66-74. https://doi.org/10.4236/ib.2019.114007

Received: October 18, 2019

Accepted: December 27, 2019

Published: December 30, 2019

Copyright (อ 2019 by author(s) and Scientific Research Publishing Inc. This work is licensed under the Creative Commons Attribution International License (CC BY 4.0).

http://creativecommons.org/licenses/by/4.0/

\begin{abstract}
As an innovative tool to leverage social capital and improve the efficiency of fiscal funds utilization, the government industry guidance fund entered the stage of rapid development under a series of favorable policies in China. But at the same time, there still exist many potential risks in its operation. How to identify and control these risks needs to be explored and summarized in theory and practice. This paper will analyze a series of risks and put forward optimization suggestions for risk management in the operation of government industry guidance fund.
\end{abstract}

\section{Keywords}

Government Industry Guidance Fund, Risk Control, Optimization Suggestion

\section{Introduction}

The government industry guidance fund is funded by the government to attract relevant financial institutions and social capital to jointly establish and support specific stage, industry and regional objectives. In December 2015, the Ministry of Finance defined the industrial guidance fund clearly in the Guidance Opinions on Government Investment Funds with Financial Funds Supporting Industry Development, which pointed out that for strategic leading industries such as integrated circuits and industry leading enterprises, direct investment can be made through the industry investment fund to achieve breakthroughs of the industry. Under the circumstances that the distribution of industrial support funds has changed from appropriation to investment, all departments have set up government guidance funds rapidly. As shown in Figure 1, the number of government guided funds has increased slightly since 2012, and entered a high-speed 


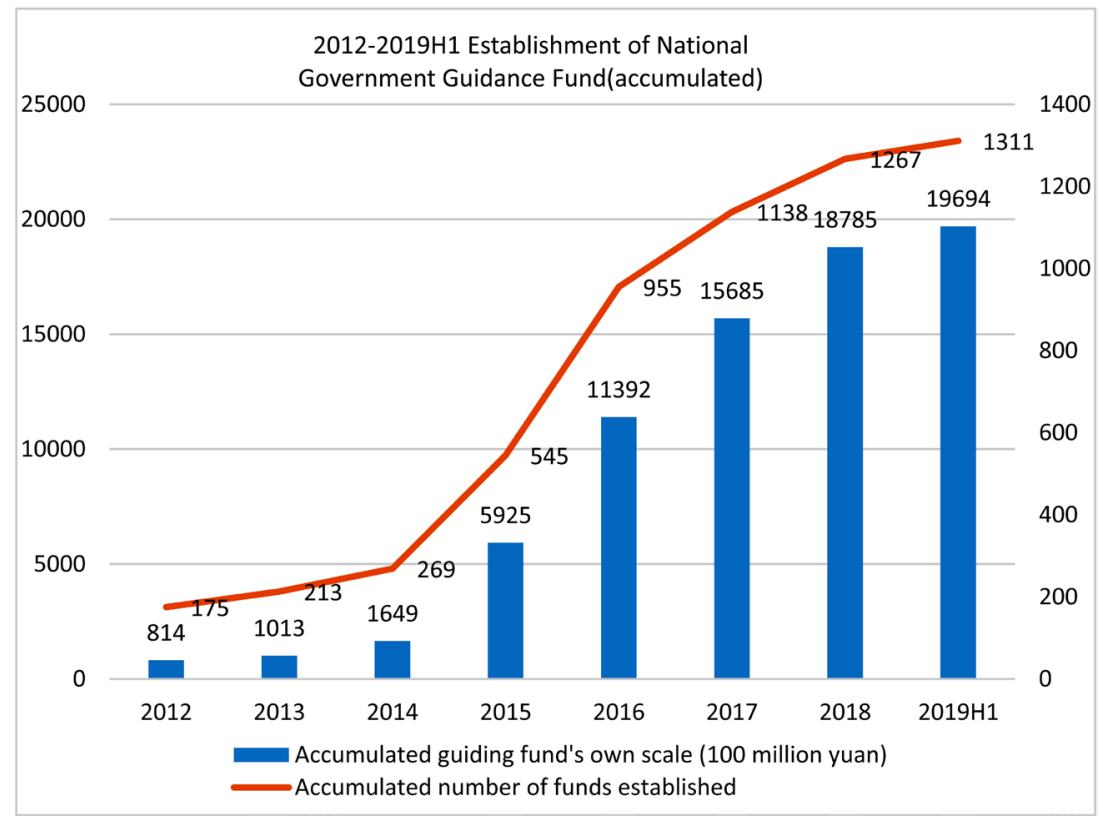

Data source: China Venture.

Figure 1. 2012-2019 H1 Establishment of national government guidance fund.

development stage after 2015. During 2012-2018, the number of guiding funds increased by 1092, with a CAGR of $39.09 \%$; the total scale of the funds increased by 1797.1 billion yuan with a CAGR of $68.74 \%$. Compared with the high-speed growth in 2015 and 2016, in 2018, the number of government guided funds and their own scale growth continued to decline on the basis of the relative slowdown trend in 2017, with the number and their total scale growth of $11.34 \%$ and $19.76 \%$ respectively.

From July 11 to 13, 2018, in the seventh WTO review of China's trade policy, industrial subsidies and other issues were mentioned again. Under the background of frequent attention to manufacturing subsidies in China, government industry support may be invisible, and industry guidance fund may be an important direction of national and policy. However, with the continuous development and expansion of the guiding fund, it also faces some difficulties in the operation and development process. In 2017, the National Development and Reform Commission issued the Guidelines for they should be registered, and they are gradually moving towards standardized supervision, but a complete and systematic supervision system has not yet been formed. Concurrently, the lack of smooth information channel caused by the problems of the internal governance anomie of guidance fund, the lack of internal restraint and incentive system, and the distortion of principal-agent relationship, etc., coupled with the influence of the power rent-seeking of managers, it is difficult to achieve the goal of policy design [1]. The insufficient market operation leads to low investment efficiency, which makes it difficult for the fund to play its guiding role fully and effectively. Therefore, how to improve the management level of the guidance fund and how to effectively control the risk of it are urgent to be solved in practice. 


\section{Literature Review}

In China, the risk management of government industry guidance fund is an area that needs further study. Liu Bowen [2] considered that how to play a guiding role and use state-owned assets to attract social capital, how to make guidance fund operate in a market-oriented way, and how to manage fund more effectively are all worthy of consideration. Ren Jie [3] studied the risks faced by the government in the whole operation of guidance fund and put forward corresponding risk management measures based on the theory of information asymmetry and the theory of principal-agent. Cao Jun [4] analyzed the main risks and causes of the guidance fund, and put forward political suggestions, such as establishing market access mechanism and improving supervision and restraint mechanism based on the perspective of principal-agent. Zhao Hongmei [5], based on the specific analysis of the representative national and local government guidance funds, divides the problems faced by the guidance funds into four stages of "raising, investing, managing and withdrawing", and gives some policy suggestions respectively.

\section{Risks of Government Industry Guidance Fund}

\subsection{System Risk Analysis}

Despite industry guidance funds develop rapidly, it still fails to avoid the policy conflict between the FOF (fund of fund) and the sub-funds. As a policy tool, FOF mainly plays a supporting and guiding role in encouraging the development of strategic emerging technology enterprises in the initial stage. While the sub-funds are market commercial venture capital funds that pursue the maximum profit and pay more attention to the growth or maturity stage of high-tech enterprises, which deviates from the initial goal of guidance fund. At present, China is in the transition stage of industrial upgrading and transformation, facing many unprecedented challenges, seeking development from labor-intensive and capital-intensive industries to technology-intensive industries. As a result, the fact that the traditional manufacturing industry has fallen sharply slowed down the growth of GDP and depressed the market. In addition, the government guidance fund is set up to support the development of new industries and high-tech industries in the seed and start-up stage in China. But the R\&D and promotion need more time and money, facing many certain factors in the process. Changes in market demand, prices, substitutes and other factors will also increase market risk. Furthermore, the guidance fund is essentially a PE fund, which will not be traded in the secondary market, and fail to be freely traded in the closed period, which will cause the fund to face greater liquidity risk.

\subsection{Unsystematic Risk Analysis}

\subsubsection{Principal-Agent Risk}

There are multiple principal-agent relationships in the operation process of guidance fund from the establishment to the selection of fund management 
companies, to the establishment of sub-funds with social capital, and finally to the investment of enterprises. It can be seen from Figure 2 that the principal-agent problems run through the whole operation of the fund. The existence of multiple principal-agent relationships will inevitably lead to information asymmetry, which also leads to the problems of adverse selection and moral hazard.

Adverse selection is based on information asymmetry; one party uses the advantage of more information than the other party to design a self-interest contract, which leads to damage the interest of other party. In the whole process of investment, in a weak position of information, government does not participate in the daily management of the fund, so it is difficult to use the limited information to fully understand the situation of sub-funds, which greatly increases the investment risk of the guidance fund. Similarly, as the client of the invested enterprise, the sub-funds are also in a weak position. Some enterprises use various means to hide their negative information to get the VC, lead to the enterprises with good value fail to get the support of guidance fund, which makes the risk of adverse selection greater.

The government does not directly participate in the management so that the guidance fund faces the moral risks brought by the managers, sub-funds management teams and entrepreneurs. They tend to make choices that are beneficial to themselves. On the one hand, fund managers cannot supervise all the processes, the invested enterprise may hide some adverse information intentionally and cheat the guidance capital. On the other hand, fund management team consider its own investment performance, income, etc., making decisions that deviate from the policy objectives when giving suggestion, so as to bring losses to the fund.

Due to the difference of interests between the principal and the agent that the failure of the principal-agent exists in the operation of guidance fund, it provides a hotbed for the generation of rent-seeking behavior in management. Rent seeking risk refers to the government use administrative power to intervene and regulate the economic activities of enterprises and individuals, hindering the role of market competition, and creating opportunities for a few privileged people to obtain excess income. Therefore, the local interests and personal interests of fund managers make the guidance fund easy to become their rent-seeking tool during policy formulation and implementation. Liu Jianjun, the main drafter of the guidance on government guidance funds issued by the financial department of the national development and Reform Commission, once said that government

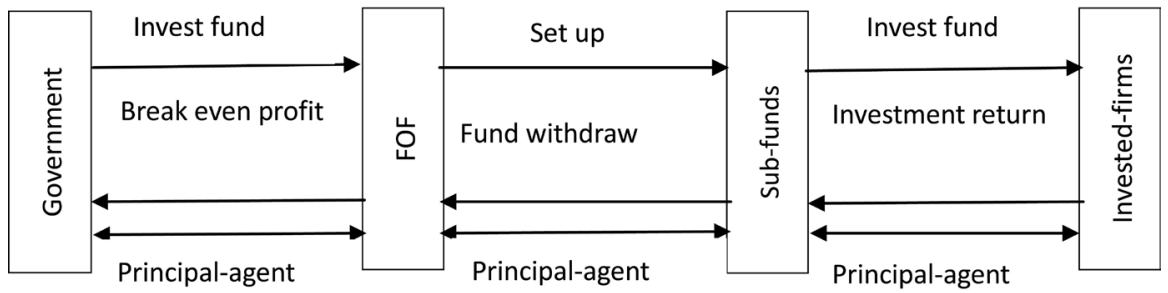

Figure 2. The principal-agent relationship in the guidance fund. 
guidance funds should rely on sound system design and be supervised before, during and after the event. Otherwise, it is likely to become a rent-seeking tool for some managers [6].

\subsubsection{Selection and Management Risk}

Choosing a good project is the key to the success of government guidance fund. But most innovative enterprises deliberately exaggerate their value and development potential to get funds, and deliberately hide adverse information, which undoubtedly increases the difficulty for managers to choose appropriate projects. In addition, some local governments will limit the investment scope, so there is a phenomenon of "choosing the right place but not the best item". Therefore, the narrow selection and few high-quality projects lower the utilization rate of funds and the rate of return. According to the statistics, at the end of 2015, 108.251 billion yuan (30\%) of the 13 funds raised by government investment funds funded and established by the central government were unused. There are similar phenomena in local government investment funds. A random inspection of 6 funds established by local governments shows that 12.4 billion yuan (66\%) of the 18.75 billion yuan invested by the government has been converted into fixed deposits of commercial banks [7]. In terms of project management, the inadequate practical investment management experience makes the guidance fund hard to provide value-added service effectively to the invested enterprises. At the same time, China's government guidance fund is still a relatively new industry with fewer compound management talents and inadequate experience in risk management of guidance fund compared with the US, Israel, Australia and other government industry guidance funds.

\subsubsection{The Exit Risk}

Exit is an important means to realize the guidance fund and capital flow. The exit risk is mainly reflected in the choice of exit mode and exit opportunity. In terms of exit mode, the main ways for guidance fund to exit are IPO, M\&A, share transfer, etc. However, due to the imperfect operation and supervision mechanism of domestic capital market and unstable operation of the stock market, the actual exit effect of many companies after IPO is not as expected. In addition, many high-tech enterprises have vague property rights relations, and China's property rights trading market system is imperfect, which made guidance fund fail to transfer property rights freely and withdraw in time. Also, it is crucial but difficult to judge the right time due to many uncertain factors. It's too early to get the ideal return, while the capital might be locked up and take more investment risks when exiting too late.

To sum up, there are many risks in the operation of government industry guidance fund. On the one hand, it is the uncontrollable influence and change brought by a series of uncertain external factors of the market itself. These inducements are mostly external to the economy and are difficult to control completely. On the other hand, it is caused by special factors, such as management 
problems, moral hazard, adverse selection and so on. However, these risks can be avoided to a certain extent by optimizing and improving some measures. Therefore, the government or guidance fund organization should take appropriate control measures to ensure that the role of industry guidance fund is fully played.

\section{Optimization of Risk Control of Industry-Guiding Fund}

\subsection{Optimization Suggestions for System Risk}

Standardizing the information disclosure mechanism to deal with the risks brought by policy and macroeconomic changes. The management team should strengthen communication to systematically and comprehensively grasp the investment situation of the sub-fund. In addition, the government should also improve the content and scope of information disclosure of Industry-guiding fund to restrict the behavior of fund managers. Major investment decisions shall be disclosed after approval, full information disclosure shall also be given for projects not yet decided to invest; a reasonable compensation mechanism shall be established to strengthen the authenticity and effectiveness of information. It is necessary to coordinate various regulatory forces to further strengthen the supervision on the investment and use of funds, so as to conform to the current development trend of government industry-oriented funds.

Carrying out market-oriented operation and avoiding liquidity risk. In the market-oriented operation of funds, it is necessary to use the market to improve the operation level and professional ability of the fund management team, at the same time, effectively mobilize the participation of social capital, and expand the channels of fund sources to banks, securities, fund management and other companies and strong enterprises or individuals. Furthermore, different return rates should be set according to priority and sub-prime for investment funds with different maturities. For example, set a shorter period and a lower return on investment for priority shares; set a higher excess return for secondary investors with holding maturity; according to the actual needs, make appropriate extension to avoid the risk of illiquidity due to the large fluctuation of fund scale [8].

\subsection{Optimization Suggestions for Unsystematic Risk}

\subsubsection{Optimization Suggestions for Principal-Agent Risk}

Introducing incentive and restraint mechanism to reduce principal-agent risk. In order to control the risk of principal-agent, enterprises can establish a suitable reward system, such as establishing an evaluation mechanism among different sub-funds to enhance the effectiveness of incentives. At the same time, it should be equipped with strict supervision measures and punishment systems, such as increasing the punishment for the company that manages and guides the fund and the investment enterprise's "failure to perform the contract". The fund investment company and the invested enterprise can also agree on the gambling clause, which requires the invested enterprise to give the agreed compensation to 
the fund investment company when it fails to achieve the expected operating objectives, and require the fund investment company to give more financial support to the invested enterprise when it exceeds the expected objectives. Finally, the government can work together with various credit management departments and fund industry associations to develop a fund credit system to collect and publish information about fund management companies' violations, so as to reduce the moral hazard caused by principal-agent.

Improving the system innovation and reduce the risk of rent-seeking. For rent-seeking risk, relevant departments should supervise it before, during and after the event to enhance the effectiveness of its control. 1) Supervision department can establish an antecedent supervision system to effectively prevent and avoid the participation of managers in rent-seeking activities. Including improving the transparency of power, implementing the hearing process; publicizing the review conclusions and investment plans of the industrial guidance fund; monitoring the decision-making behavior of managers on the platform of media and network. 2) The government can widely solicit the means of performance appraisal of fund, organically link the results of performance appraisal and the income of fund managers, promote the management of industrial guidance fund, and give full play to the leverage effect of funds. 3) The government should build a comprehensive punishment system, with administrative punishment as the main body, economic and criminal punishment as the core, and punish the violators severely.

\subsubsection{Optimization Suggestions for Project Selection and Risk Management}

Developing diversified investment methods. The source channels in China are too single, which leads to the government and fund management institutions occupying the main position in project selection, and cannot guarantee the reliability of the recommended project quality. Therefore, China's industrial guidance fund should actively expand the sources of projects and seek effective ways of project investment. For Industry-guiding Fund, it can disperse the fund in different industry fields, or choose multiple high-quality enterprises to disperse the investment in the same industry field, so as to avoid the loss caused by the single investment. For some projects with large capital demand or project risk, multiple industry guidance funds can jointly invest in the project to meet the capital demand of the project.

Guiding fund management organ to make reasonable investment decisions. For the investment project, the investment decision committee should be guided to make a reasonable investment decision. For example, it can employ external investment experts to participate in the investment decision, so as to make a more objective and fair decision evaluation. It is necessary to strengthen the communication and contact among the departments of industry and commerce, economy and information, science and technology, etc., establish a high-quality project reserve, especially introduce the enterprise information to be listed on 
the main board, gem, new third board and other capital markets, and dynamically update high-quality projects. The government department is responsible for the control of direction and policy, and the professional team is responsible for the specific operation, so as to give full play to the decision-making role of the fund's professional management team and form standardized management.

\subsubsection{Optimization Suggestions for Exit Risk}

Broadening the exit channel. A single exit channel will hinder the fund's capital circulation. Therefore, governments should constantly improve the exit mode of industrial guidance fund, broaden its exit channels, then adjust and optimize the industrial structure, and provide impetus for the development of emerging industries. The exit channels can be widened by constructing competitive advantages. On the one hand, the invested enterprise has the scarce resources such as key node technologies, products and markets in the whole industrial chain, which constitutes its own competitive advantage; On the other hand, the fund management company can find the buyer who has the demand for the invested enterprise's resources and promote the transaction through the continuous excavation and accumulation of various markets and industries. For example, various financial preferential policies are used to attract more institutional investors to participate in the fund, and encourage the establishment or introduction of foreign investment institutions. At the same time, third-party institutions should be introduced to evaluate the value of investment fairly, so as to ensure the smooth exit of early investors, put an end to the loss of assets and reduce the risks faced by investors.

Perfecting the market system of property right. Property rights trading market is an important platform for funds to exit. Therefore, while continuing to develop Shanghai Stock Exchange and Shenzhen Stock Exchange, the SME board, the GEM board should also speed up the improvement of the property rights trading market to improve the exit environment of the fund [9]. 1) The government should appropriately reduce the intervention in the property rights trading market, so as to transform the property rights trading market into the equity transfer service of various ownership enterprises. 2) The regulatory agencies should formulate unified rules of property rights market transactions to break the current situation of regional division of property rights market, so as to share information in each property rights market and form a unified and open market system. 3) The regulators can prevent the secret operation and insider trading, and strengthen the management and training of property right brokers.

\section{Conclusion}

Government industry guidance fund is still a new thing for China. Its development is a problem that the society pays much attention to in recent years, and it is also a research hotspot that the academic circles follow. Based on the analysis of the current situation of it in China, this paper analyzes its risks from both systematic and non-systematic aspects. Meanwhile, in order to give full play to 
the support and guidance effect of the fund and strengthen its risk management awareness, this paper, based on the actual situation of China, puts forward the optimization measures that the fund should take to prevent risks: coordinating the supervision and management power, standardizing the information disclosure mechanism; implementing the market-oriented operation, avoiding the liquidity risk; introducing the incentive and restraint mechanism, reducing the principal-agent risk; further guiding the fund management organization to make reasonable investment decisions, and developing diversified investment methods; improving the structure of property rights and providing an effective exit mechanism for it. Finally, the risk management measures studied in this paper are helpful to provide the government guidance fund with reference and practical suggestions, improve the management level and investment efficiency of the guidance fund, so as to better attract social capital and promote the development of high-tech enterprises in China.

\section{Funding}

Supported by 2016 Social Science Planning and Cultivation Project (2016PY42) and the Central University Basic Research Business Expense Project (SWU1909314).

\section{Conflicts of Interest}

The authors declare no conflicts of interest regarding the publication of this paper.

\section{References}

[1] Zhang, Y. (2017) On the Problems and Solutions of Government Industry Guiding the Development of Investment Funds. Money China, 2, 108.

[2] Liu, B.W. (2017) Reflections on Government Industry Guidance Fund. Tianjin Economy, 11, 24-27.

[3] Ren, J. (2014) Research on Risk Management of Government Guidance Fund [D]. Tianjin University,

[4] Cao, J. (2011) Construction of Risk Prevention System of China's Government Guidance Fund. Business Age, 7, 52-53.

[5] Zhao, H.M. (2019) Research on the Development and Countermeasures of Chinese Government Guidance Fund in Tech Finance. Business Economy, 6, 167-168, 186.

[6] Zhang, L., Hou, J., Wang, Z.M. (2011) Risk Prevention of Government Guided Fund Rent-Seeking. Science and Technology Management Research, 31, 37-39.

[7] Jiang, L. (2018) Government Guided Fund: 12 Trillion Dilemma and Contradiction. http://www.sohu.com/a/282040292_480400.\%202018

[8] Wang, X.J. (2019) Research on the Risk Prevention and Control of Private Equity Investment Fund in China. Consume Guide, 11, 170.

[9] Yan, F. (2019) Research on the Problems and Countermeasures of the Government Industry-Guiding Fund in China. Information Week, 15, 0200-0200. 